\title{
Rivaroxaban Versus Low-molecular-weight Heparin for Venous Thromboembolism in Advanced Upper Gastrointestinal Tract and Hepatopancreatobiliary Cancer
}

\author{
JWA HOON KIM*, SEYOUNG SEO*, KYU-PYO KIM, HEUNG-MOON CHANG, \\ BAEK-YEOL RYOO, CHANGHOON YOO, JAE HO JEONG, JAE-LYUN LEE, HYEON-SU IM, \\ HYEHYUN JEONG, YEONGHAK BANG and SOOK RYUN PARK
}

Department of Oncology, Asan Medical Center, University of Ulsan College of Medicine, Seoul, Republic of Korea

\begin{abstract}
Background/Aim: The aim of this study was to examine the efficacy and safety of direct oral anticoagulants for cancer-associated venous thromboembolism (VTE) in patients with active cancer. Patients and Methods: This study included patients with advanced unresectable/metastatic upper gastrointestinal (GI) or hepatopancreatobiliary (HPB) cancers with high risks of VTE and bleeding. Results: No significant differences were noted in potential bleeding factors between the rivaroxaban $(n=105)$ and low-molecular-weight heparin (LMWH) (n=69) groups. Rivaroxaban exhibited similar risk of recurrent/aggravated VTE compared with LMWH $(p=0.625)$ but increased risk of major bleeding (17.4\% vs. $7.6 \% ; p=0.072)$, clinically relevant bleeding $(31.9 \% \mathrm{vs}$. $14.3 \% ; p=0.019)$, and total bleeding (40.6\% vs. 19\%; $p=0.010)$. The multivariate analysis regarded rivaroxaban as a significant factor for major bleeding $(p=0.043)$ and clinically relevant bleeding $(p=0.043)$. Conclusion: Rivaroxaban exhibits comparable efficacy but increases bleeding risks compared with LMWH in patients with active unresectable/metastatic upper GI tract or HPB cancers, requiring extra caution of higher major bleeding risks.
\end{abstract}

As cancer-associated venous thromboembolism (VTE) might cause a delay or discontinuation of anticancer treatments (1),

This article is freely accessible online.

*These Authors contributed equally to this study.

Correspondence to: Sook Ryun Park, MD, Ph.D., Department of Oncology, Asan Medical Center, University of Ulsan College of Medicine, 88 Olympic-ro 43-gil, Songpa-gu, Seoul 05505, Republic of Korea. Tel: +82 230103206, e-mail: srpark@amc.seoul.kr

Key Words: Rivaroxaban, low-molecular-weight heparin, venous thromboembolism, gastrointestinal tract cancer, hepatopancreatobiliary cancer. optimal management of VTE is essential in patients with cancer. The anticoagulation treatment in cancer-associated VTE is especially challenging in balancing the risks of recurrent VTE and bleeding during anticoagulation $(2,3)$. Randomized phase III trials have established that long-term low-molecular-weight heparins (LMWHs), such as dalteparin, correlated with better or similar efficacy and safety than vitamin $\mathrm{K}$ antagonists (VKAs) maintenance in patients with cancer (4-6). Accordingly, LMWH has been preferred over VKA for the treatment of cancer-associated thrombosis (7-9).

Owing to convenience in administration and monitoring, direct oral anticoagulants (DOACs), including factor $\mathrm{Xa}$ inhibitors and thrombin inhibitors, have emerged with expectation to replace oral VKAs or LMWHs, as prophylactic and therapeutic anticoagulation options. In two large randomized studies comparing rivaroxaban, an oral factor Xa inhibitor, with enoxaparin followed by VKA maintenance for the treatment of deep-vein thrombosis (DVT) (EINSTEIN-DVT) and pulmonary embolism (EINSTEIN-PE), rivaroxaban demonstrated noninferior efficacy with similar risk for bleeding $(10,11)$. Other DOACs, including apixaban (12), edoxaban (13), and dabigatran (14), also showed noninferior efficacy and a similar or lower bleeding risk in patients with VTE compared with an oral VKA. However, these studies were not cancer-specific, and only $<10 \%$ of patients had cancer, including cancer history only. Although a subgroup analysis of EINSTEIN-DVT and EINSTEIN-PE and a meta-analysis comparing DOAC and VKA in patients with cancer exhibited similar efficacy and safety between DOAC and VKA, these studies examined not only patients with cancer during anticoagulation but also patients whose cancer had already been treated $(15,16)$. Indeed, the proportion of patients with recurrent or metastatic cancer was only $22 \%$ in the subgroup analysis of EINSTEIN-DVT and EINSTEINPE studies (15). In addition, although two cancer-specific randomized trials comparing DOAC and dalteparin in 
Table I. Baseline characteristics of study patients.

\begin{tabular}{|c|c|c|c|}
\hline & $\begin{array}{c}\text { Rivaroxaban } \\
(\mathrm{n}=69, \%)\end{array}$ & $\begin{array}{c}\text { LMWH } \\
(\mathrm{n}=105, \%)\end{array}$ & $p$-Value \\
\hline \multicolumn{4}{|l|}{ Types of LMWH } \\
\hline Dalteparin & - & $57(54.3 \%)$ & \\
\hline Enoxaparin & - & $48(45.7 \%)$ & \\
\hline Age, years & $67(59-72)$ & $59(52-66)$ & 0.007 \\
\hline$\geq 65$ years & $38(55.1)$ & $30(28.6)$ & \\
\hline Gender & & & 0.369 \\
\hline Male & $32(46.4)$ & $56(53.3)$ & \\
\hline Primary cancer type & & & 0.074 \\
\hline Esophageal cancer & $1(1.4)$ & $7(6.7)$ & \\
\hline Gastric cancer & $22(31.9)$ & $51(48.6)$ & \\
\hline Gastric GIST & $1(1.4)$ & $1(1.0)$ & \\
\hline $\mathrm{HCC}$ & $3(4.3)$ & $5(4.8)$ & \\
\hline Biliary cancer & $14(20.3)$ & $16(15.2)$ & \\
\hline Pancreatic cancer & $27(39.1)$ & $25(23.8)$ & \\
\hline Ampulla of Vater cancer & $1(1.4)$ & $0(0)$ & \\
\hline Disease status at diagnosis of VTE & & & 0.505 \\
\hline Locally advanced unresectable & $11(15.9)$ & $13(12.4)$ & \\
\hline Metastatic or recurrent & $58(84.1)$ & $92(87.6)$ & \\
\hline Type of VTE & & & 0.308 \\
\hline DVT only & $33(47.8)$ & $48(45.7)$ & \\
\hline PE only & $19(27.5)$ & $39(37.1)$ & \\
\hline Both DVT and PE & $17(24.6)$ & $18(17.1)$ & \\
\hline ECOG performance status & & & 0.006 \\
\hline $0-1$ & $65(94.2)$ & $83(79.0)$ & \\
\hline $2-4$ & $4(5.8)$ & $22(21.0)$ & \\
\hline BMI $(<18.5 \mathrm{~kg} / \mathrm{m} 2)$ & $14(20.3)$ & $13(12.4)$ & 0.159 \\
\hline Platelet count $\left(<100 \times 10^{6} / \mu \mathrm{l}\right)$ & $4(5.8)$ & $14(13.3)$ & 0.110 \\
\hline Creatinine clearance $(<60 \mathrm{ml} / \mathrm{min})$ & $6(8.7)$ & $9(8.6)$ & 0.977 \\
\hline Exposure to anticancer systemic therapy during anticoagulation & $40(58.0)$ & $49(46.7)$ & 0.144 \\
\hline Exposure to radiotherapy during anticoagulation & $4(5.8)$ & $9(8.6)$ & 0.496 \\
\hline Cancer lesions at GI tract mucosa & $20(29.0)$ & $43(41.0)$ & 0.108 \\
\hline Past medical history of bleeding & $4(5.8)$ & $6(5.7)$ & 1.000 \\
\hline $\begin{array}{l}\text { Duration from diagnosis of unresectable, metastatic, or recurrent } \\
\text { cancer to the start of anticoagulation, months }\end{array}$ & $3.2(1.6-6.0)$ & $4.2(1.4-8.5)$ & 0.275 \\
\hline
\end{tabular}

Data are median (interquartile range) or number (\%). LMWH: Low-molecular-weight heparin; GIST: gastrointestinal stromal tumor; HCC, hepatocellular carcinoma; VTE: venous thromboembolism; DVT: deep-vein thrombosis; PE: pulmonary embolism; ECOG: Eastern Cooperative Oncology Group; BMI: body mass index; GI: gastrointestinal.

patients with cancer were conducted $(17,18)$, patients without active cancer lesions during anticoagulation were still included, and cancers consisted of various types and stages that had variable risks of VTE and bleeding.

This retrospective study aimed to investigate the efficacy and safety of rivaroxaban compared with LMWH as a treatment for VTE in patients with active locally advanced unresectable or metastatic cancers, especially upper gastrointestinal (GI) tract and hepatopancreatobiliary (HPB) cancer that have high risks of VTE and bleeding $(19,20)$.

\section{Patients and Methods}

Study population. Using the electronic medical records database system, we identified 994 patients diagnosed with upper GI tract and HPB cancer and received LMWH (dalteparin or enoxaparin; $n=777)$ or rivaroxaban $(n=217)$ from January 2004 to December 2014 at the Asan Medical Center (Seoul, Republic of Korea). Of these, patients with locally advanced unresectable or metastatic disease at the start of anticoagulation who were treated with LMWH or rivaroxaban for therapeutic purposes of DVT or PE for 14 days unless discontinued because of bleeding were eligible for this study. We included 174 eligible patients (rivaroxaban group, 69; LMWH group, 105). This study was approved by the Institutional Review Board of the Asan Medical Center, and all information was obtained with appropriate Institutional Review Board waivers.

Treatment. The selection of LMWH or rivaroxaban for documented VTE (DVT and/or PE) was at the physicians' discretion. Following the institutional routine practice for cancer-associated VTE, the treatment duration was planned for 6 months unless VTE persisted, but the completion of anticoagulation was individualized per the 
Table II. Recurrent or aggravated venous thromboembolism and bleeding events.

\begin{tabular}{|c|c|c|c|c|c|}
\hline & $\begin{array}{c}\text { Rivaroxaban } \\
(\mathrm{n}=69, \%)\end{array}$ & $\begin{array}{c}\text { LMWH } \\
(\mathrm{n}=105, \%)\end{array}$ & $p$-Value & HR $(95 \% \mathrm{CI})$ & $p$-Value \\
\hline Recurrent or aggravated VTE & $2(2.9)$ & $1(1.0)$ & 0.563 & $1.86(0.15-22.60)$ & 0.625 \\
\hline \multicolumn{6}{|l|}{ Category of bleeding events } \\
\hline Major bleeding & $12(17.4)$ & $8(7.6)$ & 0.048 & $2.28(0.93-5.57)$ & 0.072 \\
\hline Clinically relevant non-major bleeding & $10(14.5)$ & $7(6.7)$ & 0.117 & $2.14(0.82-5.64)$ & 0.122 \\
\hline Clinically relevant bleeding & $22(31.9)$ & $15(14.3)$ & 0.006 & $2.20(1.14-4.24)$ & 0.019 \\
\hline Total bleeding & $28(40.6)$ & $20(19.0)$ & 0.002 & $2.13(1.10-3.79)$ & 0.010 \\
\hline
\end{tabular}

LMWH: Low-molecular-weight heparin; HR: hazard ratio; CI: confidence interval; VTE: venous thromboembolism.

physicians' decision and clinical conditions. The doses and schedules of LMWH (dalteparin or enoxaparin) and rivaroxaban were standard dosing schedules-dalteparin was administered subcutaneously once daily at a dose of $200 \mathrm{IU} / \mathrm{kg}$ for the first 30 days of treatment, and then at $150 \mathrm{IU} / \mathrm{kg}$; enoxaparin was administered subcutaneously twice daily with at a dose of $1 \mathrm{mg} / \mathrm{kg}$; and rivaroxaban was administered orally twice daily at a dose of 15 $\mathrm{mg}$ for the first 21 days of treatment, and then once daily at $20 \mathrm{mg}$.

Efficacy and safety outcomes. We evaluated the efficacy outcomes with recurrent or aggravated DVT or PE during follow-up. The aggravation of DVT or PE was documented by the same diagnostic methods as those used for the initial diagnosis. Recurrent or aggravated VTE was defined as one of the following: (1) new intraluminal filling defects of venous segment in two or more views on Computed Tomography (CT); (2) new noncompressible venous segments on ultrasonography; (3) a substantial increase ( $\geq 4 \mathrm{~mm}$ ) in the diameter of the thrombus during full compression in a previously abnormal segment on ultrasonography; (4) new perfusion defect of, at least, $75 \%$ of a segment with corresponding normal ventilation (high probability) on perfusion scan, or (5) new lesions correlated with DVT documented by CT or ultrasonography despite non-high-probability perfusion defect on perfusion scan; (6) fatal PE based on objective diagnostic tests, which could not be attributed to a documented cause and for which could not be ruled out (unexplained death). The safety outcomes were evaluated with bleeding events, which were classified into three categories - major bleeding, clinically relevant non-major bleeding, and total bleeding - as reported previously $(17,21)$. Major bleeding was defined as acute and clinically overt bleeding accompanied by one or more of the following: contribution to death, occurrence in critical sites such as intracranial site, a decrease in the hemoglobin level $\geq 2 \mathrm{~g} / \mathrm{dl}$, or the need for the transfusion of $\geq 2$ units of red blood cells. In case of not fulfilling the criteria for major bleeding, clinically relevant non-major bleeding was defined as acute and clinically overt bleeding with one or more of the following: the need for medical intervention, unscheduled contact with a physician, or interruption or discontinuation of anticoagulation. The clinically relevant bleeding was defined as the sum of major bleeding and clinically relevant non-major bleeding.

Statistical analysis. Categorical and quantitative data were compared using the Chi-square test or Fisher's exact test and Mann-Whitney $U$ test, respectively. We calculated the time to recurrent or aggravated VTE and bleeding from the beginning of anticoagulation to the date of recurrence or aggravation of VTE, and the date of the first episode of bleeding, respectively. Patients without any event were censored at the time of the last follow-up. Eight patients switching anticoagulants without any event at the physicians' discretion were censored at the stopping date of corresponding anticoagulants. Using the KaplanMeier method and log-rank test, we estimated and compared the timeto-event distribution, respectively. Cox proportional hazards models were used to estimate the correlation between the type of anticoagulation and the time to event. The multivariate analysis included significant factors $(p<0.1)$ in the univariate analysis, and the backward elimination model was used in the multivariate analysis. Logistic regression model was used to calculate odd ratios of bleeding events according to the type of anticoagulant in GI tract cancers versus non-GI tract cancers. The interaction test was performed in the logistic regression models to assess whether the bleeding event rates of each anticoagulant differed between GI and non-GI tract cancer. All tests were two-sided with $5 \%$ defined as the level of significance.

\section{Results}

Patient characteristics. Table I summarizes the baseline characteristics of the study patients. Most patients $(n=150$, $86.2 \%$ ) had metastatic or recurrent cancers, and 94 patients $(54.0 \%)$ were concurrently treated with anticancer systemic therapy during anticoagulation. The median time to the start of anticoagulation from the diagnosis of unresectable, metastatic, or recurrent cancer was 4.6 [interquartile range $(I Q R)=2.0-9.6]$ months. The median age was higher in the rivaroxaban group than in the LMWH group (67vs. 59 years; $p=0.007)$, whereas patients with the Eastern Cooperative Oncology Group performance status $\geq 2(21.0 \%$ vs. $5.8 \% ; p=0.006)$ and GI cancer as the primary cancer type (56.2\% vs. $36.2 \% ; p=0.013$ ) were more common in the LMWH group than that in the rivaroxaban group. The frequency of thrombocytopenia $<100 \times 10^{6} / \mu 1$ also tended to be higher in the LMWH group (13.3\% vs. $5.8 \%$; $p=0.110)$.

Anticoagulation treatment. The median treatment duration of an initially started anticoagulant was $55(\mathrm{IQR}=27-131)$ days in the rivaroxaban group and $44(\mathrm{IQR}=23-95)$ days in the LMWH group ( $p=0.345)$. Most patients could not maintain the initial anticoagulant as planned because of bleeding 


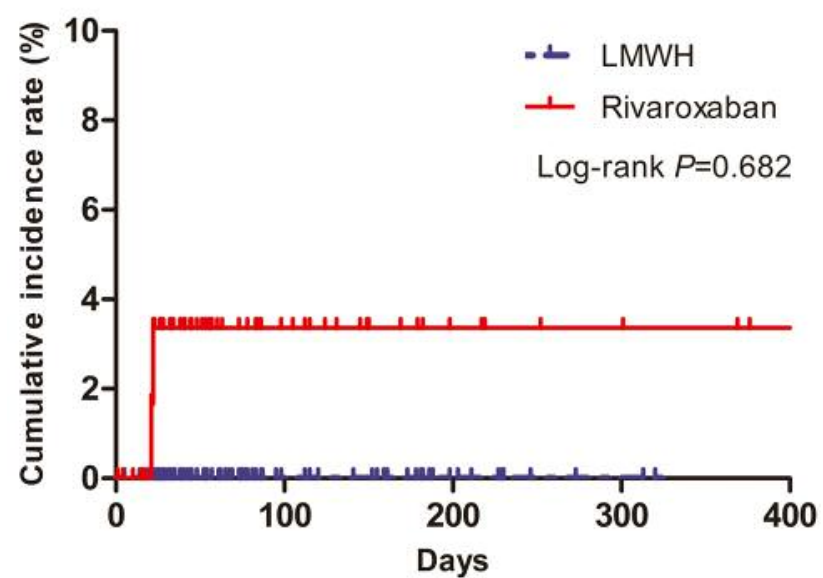

Figure 1. The Kaplan-Meier estimate of the time to recurrent or aggravated venous thromboembolism.

$(n=38,21.8 \%)$, follow-up loss $(n=52,29.9 \%)$, death with cancer progression $(n=27,15.5 \%)$, switching to other anticoagulants for recurrent or aggravated VTE events $(n=3$, $1.7 \%)$, physicians' discretion $(n=8,4.6 \%)$, and other reasons $(n=18,10.3 \%)$, including thrombocytopenia, procedure, poor general condition, or sepsis with coagulopathy.

Efficacy and safety outcomes. Recurrent or aggravated VTE occurred in 1 patient $(1.0 \%)$ in the LMWH group and 2 patients $(2.9 \%)$ in the rivaroxaban group $(p=0.563)$. The comparison of the time to recurrence and aggravation of VTE revealed that the efficacy in the rivaroxaban group was not significantly different from that in the LMWH group [hazard ratio (HR), 1.86; 95\% confidence interval $(\mathrm{CI})=0.15$ 22.60; $p=0.625]$ (Table II, Figure 1).

Overall, 12 patients in the rivaroxaban group (17.4\%) and 8 in the LMWH group (7.6\%) had major bleeding events ( $p=0.048)$ and, regarding time to major bleeding, an increasing trend was observed in the rivaroxaban group compared to the LMWH group $(\mathrm{HR}=2.28,95 \% \mathrm{CI}=0.93$ 5.57, $p=0.072$ ) (Figure 2a; Table II). In addition, both clinically relevant bleeding and total bleeding events were more often observed in the rivaroxaban group than in the LMWH group-31.9\% vs. $14.3 \%$ ( $p=0.006)$ with HR 2.20 $(95 \% \mathrm{CI}=1.14-4.24, p=0.019)$ for clinically relevant bleeding; and $40.6 \%$ vs. $19.0 \%$ ( $p=0.002)$ with HR 2.13 (95\% CI=1.20$3.79, p=0.010$ ) for total bleeding (Figure $2 \mathrm{~b}$ and $\mathrm{c}$; Table II). Table III summarizes the univariate analysis of clinical factors for major bleeding and clinically relevant bleeding. The type of anticoagulant remained the significant factor associated with the risk of major bleeding $(\mathrm{HR}=2.55$; 95\% CI $=1.03-6.31 ; p=0.043)$ and clinically relevant bleeding $(\mathrm{HR}=2.54 ; 95 \% \mathrm{CI}=1.03-6.25 ; p=0.043)$ in the multivariate analysis (Table III). Table IV presents the frequencies of

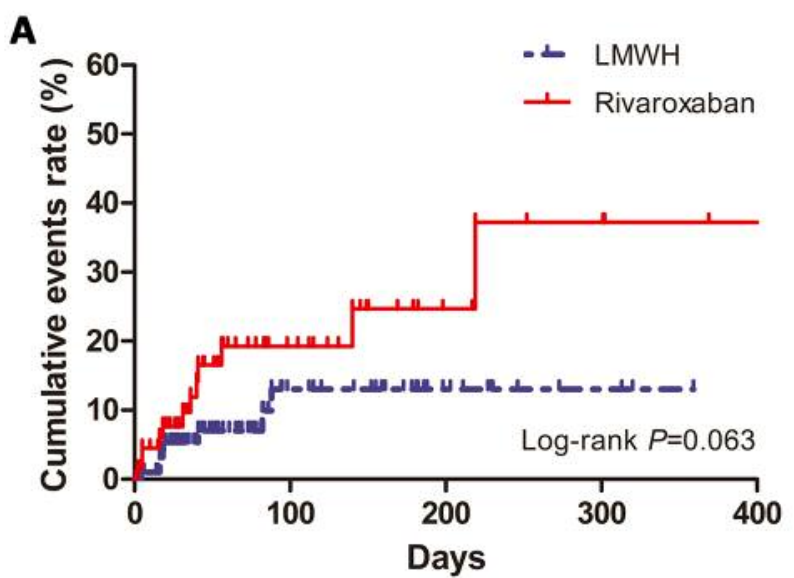

B
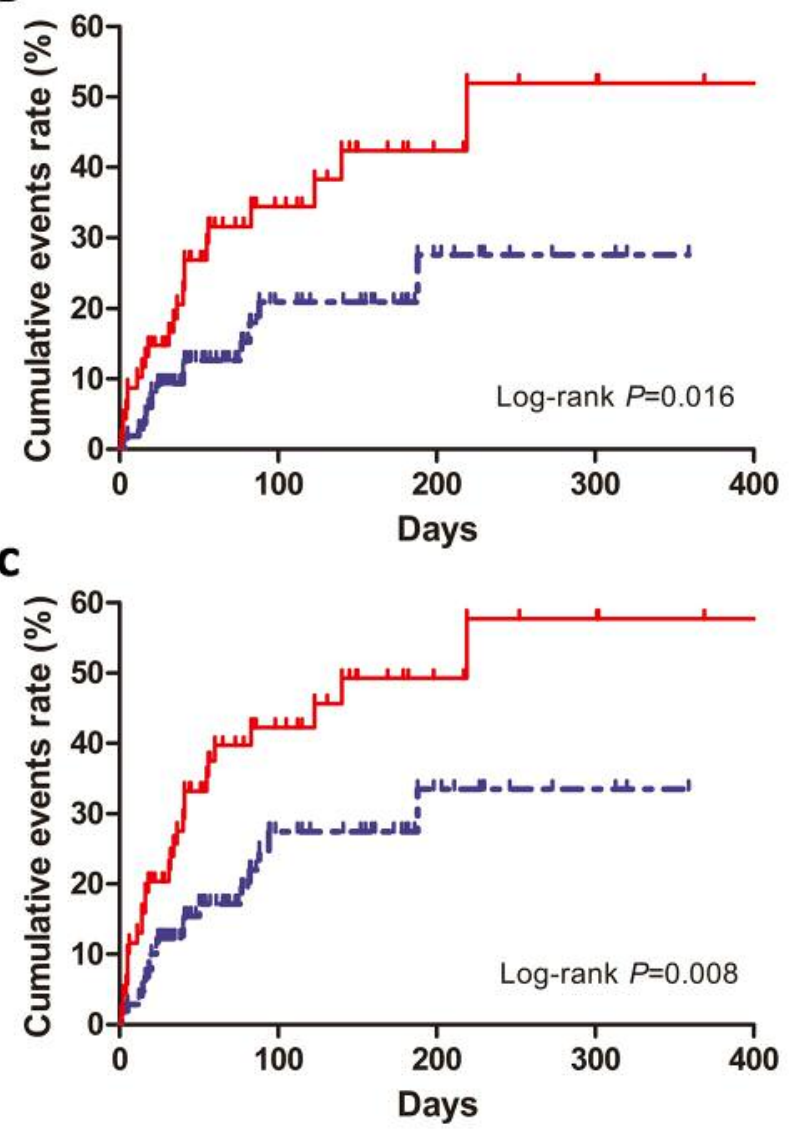

Figure 2. The Kaplan-Meier estimate of the time to bleeding. A: Major bleeding; B: Clinically relevant bleeding (major and non-major bleeding); and $C$ : Total events of bleeding.

bleeding events per the type of anticoagulant in GI tract cancer versus non-GI tract cancer. Patients with GI tract cancers were more likely to have an increase in the risk of major bleeding with rivaroxaban than with LMWH (interaction $p=0.041$ ). The frequencies of bleeding events per 
Table III. Univariate and multivariate analysis of clinical factors for major bleeding and clinically relevant bleeding.

\begin{tabular}{|c|c|c|c|c|c|c|c|c|}
\hline & \multicolumn{4}{|c|}{ Major bleeding } & \multicolumn{4}{|c|}{ Clinically relevant bleeding } \\
\hline & \multicolumn{2}{|c|}{ Univariate } & \multicolumn{2}{|c|}{ Multivariate } & \multicolumn{2}{|c|}{ Univariate } & \multicolumn{2}{|c|}{ Multivariate } \\
\hline & HR $(95 \% \mathrm{CI})$ & $p$-Value & HR $(95 \% \mathrm{CI})$ & $p$-Value & HR $(95 \% \mathrm{CI})$ & $p$-Value & HR $(95 \% \mathrm{CI})$ & $p$-Value \\
\hline Female $v s$. male & $\begin{array}{c}0.69 \\
(0.28-1.74)\end{array}$ & 0.431 & & & $\begin{array}{c}1.19 \\
(0.63-2.28)\end{array}$ & 0.590 & & \\
\hline $\begin{array}{l}\text { Age } \geq 65 \text { years } \\
v s .<65 \text { years }\end{array}$ & $\begin{array}{c}1.31 \\
(0.54-3.17)\end{array}$ & 0.547 & & & $\begin{array}{c}1.51 \\
(0.79-2.88)\end{array}$ & 0.212 & & \\
\hline $\begin{array}{l}\text { ECOG } \mathrm{PS} \geq 2 v s \\
\mathrm{ECOG} \text { PS }<2\end{array}$ & $\begin{array}{c}1.44 \\
(0.42-4.95)\end{array}$ & 0.563 & & & $\begin{array}{c}1.58 \\
(0.66-3.81)\end{array}$ & 0.309 & & \\
\hline $\begin{array}{l}\text { BMI }(<18.5) v s . \\
\operatorname{BMI}(\geq 18.5)\end{array}$ & $\begin{array}{c}0.97 \\
(0.28-3.30)\end{array}$ & 0.957 & & & $\begin{array}{c}1.29 \\
(0.57-2.95)\end{array}$ & 0.541 & & \\
\hline $\begin{array}{l}\text { Platelet }<100 \times 10^{6} / \mu 1 \\
v s . \geq 100 \times 10^{6} / \mu 1\end{array}$ & $\begin{array}{c}2.48 \\
(0.90-6.84)\end{array}$ & 0.079 & $\begin{array}{c}2.93 \\
(1.05-8.18)\end{array}$ & 0.041 & $\begin{array}{c}1.74 \\
(0.77-3.97)\end{array}$ & 0.186 & & \\
\hline $\begin{array}{l}\text { Cr clearance }<60 \mathrm{ml} / \mathrm{min} \\
v s . \geq 60 \mathrm{ml} / \mathrm{min}\end{array}$ & $\begin{array}{c}2.17 \\
(0.63-7.49)\end{array}$ & 0.220 & & & $\begin{array}{c}1.06 \\
(0.32-3.48)\end{array}$ & 0.921 & & \\
\hline $\begin{array}{l}\text { Anticancer systemic } \\
\text { therapy during } \\
\text { anticoagulation } \\
\text { (yes } v s . \text { no) }\end{array}$ & $\begin{array}{c}0.52 \\
(0.21-1.30)\end{array}$ & 0.164 & & & $\begin{array}{c}0.50 \\
(0.26-0.99)\end{array}$ & 0.046 & $\begin{array}{c}0.33 \\
(0.13-0.83)\end{array}$ & 0.018 \\
\hline $\begin{array}{l}\text { Radiotherapy during } \\
\text { anticoagulation } \\
\text { (yes vs.no) }\end{array}$ & $\begin{array}{c}2.17 \\
(0.63-7.40)\end{array}$ & 0.217 & & & $\begin{array}{c}1.10 \\
(0.34-3.59)\end{array}$ & 0.873 & & \\
\hline $\begin{array}{l}\text { Cancer lesions at GI } \\
\text { mucosa (yes vs. no) }\end{array}$ & $\begin{array}{c}1.51 \\
(0.63-7.40)\end{array}$ & 0.217 & & & $\begin{array}{c}1.17 \\
(0.61-2.24)\end{array}$ & 0.643 & & \\
\hline $\begin{array}{l}\text { Type of anticoagulant } \\
\text { (rivaroxaban } v s . \mathrm{LMWH} \text { ) }\end{array}$ & $\begin{array}{c}2.28 \\
(0.93-5.57)\end{array}$ & 0.072 & $\begin{array}{c}2.55 \\
(1.03-6.31)\end{array}$ & 0.043 & $\begin{array}{c}2.20 \\
(1.14-4.24)\end{array}$ & 0.019 & $\begin{array}{c}2.54 \\
(1.03-6.25)\end{array}$ & 0.043 \\
\hline
\end{tabular}

HR: Hazard ratio; CI: confidence interval; ECOG: Eastern Cooperative Oncology Group; PS: performance status; BMI, body mass index; Cr: creatinine; GI: gastrointestinal.

the type of anticoagulant in each primary cancer type are shown in Table V. The most common bleeding site was the GI tract; all major bleeding in the rivaroxaban group, and half of the major bleeding cases in the LMWH group occurred in the GI tract (Table VI).

\section{Discussion}

International guidelines $(9,22,23)$ recommend LMWH as the preferred anticoagulant treatment of cancer-associated VTE based on the better or similar efficacy and safety results of LMWH over VKA in patients with cancer (4-6). Recently, DOACs have emerged as the treatment option for VTE in clinical practice based on their noninferior efficacy and safety results compared with VKA in non-cancer-specific clinical trials (10-14). In the latest-version of the National Comprehensive Cancer Network guidelines (22), DOACs, including rivaroxaban, apixaban, and edoxaban, have been adopted as acceptable alternatives for the treatment of cancer-associated VTE (22). As patients with active cancer have higher risks of recurrent VTE and bleeding complication than non-cancer patients, the efficacy and safety of an anticoagulation regimen warrant separate investigation in patients with active cancer. A randomized pilot trial (SELECT-D) comparing rivaroxaban and dalteparin in patients with active cancer showed that rivaroxaban correlated with lower VTE recurrence (HR=0.43; 95\%CI=0.19-0.99), but a higher occurrence of clinically relevant non-major bleeding (HR, 3.76; 95\% CI=1.63-8.69) (17). Another randomized trial (Hokusai VTE cancer study) comparing edoxaban and dalteparin in patients with active cancer or cancer diagnosed within the previous 2 years reported that the rate of recurrent VTE tended to be lower with edoxaban $(\mathrm{HR}=0.71 ; 95 \% \mathrm{CI}=0.48$ 1.06); however, the rate of major bleeding was significantly higher with edoxaban than that with dalteparin $(\mathrm{HR}=1.77$; 95\% CI=1.03-3.04) (18). These studies demonstrated the higher risk of bleeding of DOACs compared with dalteparin in patients with cancer contrary to previous non-cancerspecific trials that suggested DOACs had less major bleeding events compared with lead-in enoxaparin followed by VKA in patients with cancer (15).

Nevertheless, some crucial points merit further discussion in these two cancer-specific trials $(17,18)$. First, in both 
in vivo $34: 829-837(2020)$

Table IV. The frequency of bleeding events according to the type of anticoagulant in gastrointestinal (GI) tract cancer versus non-GI tract cancer.

\begin{tabular}{|c|c|c|c|c|c|c|c|c|c|}
\hline & \multicolumn{4}{|c|}{ GI tract cancer $(n=84)$} & \multicolumn{4}{|c|}{ Non-GI tract cancer $(n=90)$} & \multirow[b]{2}{*}{$p_{\text {interaction }} \mathrm{b}$} \\
\hline & $\begin{array}{c}\text { Rivaroxaban } \\
(\mathrm{n}=25, \%)\end{array}$ & $\begin{array}{l}\text { LMWH } \\
(\mathrm{n}=59, \%)\end{array}$ & OR $(95 \% \mathrm{CI})$ & $p$-Value & $\begin{array}{c}\text { Rivaroxaban } \\
(\mathrm{n}=44, \%)\end{array}$ & $\begin{array}{l}\text { LMWH } \\
(\mathrm{n}=46, \%)\end{array}$ & OR $(95 \% \mathrm{CI})$ & $p$-Value & \\
\hline Major bleeding & $6(24.0)^{\mathrm{a}}$ & $4(6.8)$ & $\begin{array}{c}4.34 \\
(1.11-17.06)\end{array}$ & 0.035 & $6(13.6)$ & $4(8.7)$ & $\begin{array}{c}1.66 \\
(0.44-6.33)\end{array}$ & 0.459 & 0.041 \\
\hline $\begin{array}{l}\text { Clinically relevant } \\
\text { non-major bleeding }\end{array}$ & $3(12.0)$ & $6(10.2)$ & $\begin{array}{c}1.21 \\
(0.28-5.25)\end{array}$ & 0.804 & $7(15.9)^{\mathrm{a}}$ & $1(2.2)$ & $\begin{array}{c}8.51 \\
(1.00-72.36)\end{array}$ & 0.050 & 0.686 \\
\hline $\begin{array}{l}\text { Clinically relevant } \\
\text { bleeding }\end{array}$ & $9(36.0)$ & $10(16.9)$ & $\begin{array}{c}2.76 \\
(0.95-7.98)\end{array}$ & 0.062 & $13(29.5)^{\mathrm{a}}$ & $5(10.9)$ & $\begin{array}{c}3.44 \\
(1.11-10.67)\end{array}$ & 0.032 & 0.057 \\
\hline Total bleeding & $10(40.0)$ & $13(22.0)$ & $\begin{array}{c}2.36 \\
(0.86-6.47)\end{array}$ & 0.096 & $18(40.9)^{\mathrm{a}}$ & $7(15.2)$ & $\begin{array}{c}3.86 \\
(1.41-10.53)\end{array}$ & 0.008 & 0.138 \\
\hline
\end{tabular}

LMWH: Low-molecular-weight heparin; OR: odds ratio; CI: confidence interval; GI: gastrointestinal. aSignificant $p$-Value using the chi-square test or Fisher's exact test. ' Interaction test was performed to assess whether the bleeding event rates of each anticoagulant differed between the GI and non-GI tract cancer.

Table V. The frequency of bleeding events according to the type of anticoagulant in each primary cancer type.

\begin{tabular}{|c|c|c|c|c|c|c|}
\hline & \multicolumn{3}{|c|}{ Gastric cancer $(n=73)$} & \multicolumn{3}{|c|}{ Non-gastric cancer $(n=101)$} \\
\hline & $\begin{array}{c}\text { Rivaroxaban } \\
(\mathrm{n}=22, \%)\end{array}$ & $\begin{array}{l}\text { LMWH } \\
(\mathrm{n}=51, \%)\end{array}$ & $p$-Value & $\begin{array}{c}\text { Rivaroxaban } \\
(\mathrm{n}=47, \%)\end{array}$ & $\begin{array}{l}\text { LMWH } \\
(\mathrm{n}=54, \%)\end{array}$ & $p$-Value \\
\hline Major bleeding & $6(27.3)$ & $3(5.9)$ & 0.018 & $6(12.8)$ & $5(9.3)$ & 0.573 \\
\hline Clinically relevant non-major bleeding & $3(13.6)$ & $6(11.8)$ & 0.823 & $7(14.9)$ & $1(1.9)$ & 0.024 \\
\hline Clinically relevant bleeding & $9(40.9)$ & $9(17.6)$ & 0.034 & $13(27.7)$ & $6(11.1)$ & 0.034 \\
\hline \multirow[t]{3}{*}{ Total bleeding } & $9(40.9)$ & $11(21.6)$ & 0.089 & $19(40.4)$ & $9(16.7)$ & 0.008 \\
\hline & \multicolumn{3}{|c|}{ Pancreas cancer $(\mathrm{n}=52)$} & \multicolumn{3}{|c|}{ Biliary cancer $(n=30)$} \\
\hline & $\begin{array}{c}\text { Rivaroxaban } \\
(\mathrm{n}=25, \%)\end{array}$ & $\begin{array}{l}\text { LMWH } \\
(\mathrm{n}=27, \%)\end{array}$ & $p$-Value & $\begin{array}{c}\text { Rivaroxaban } \\
(\mathrm{n}=14, \%)\end{array}$ & $\begin{array}{l}\text { LMWH } \\
(\mathrm{n}=16, \%)\end{array}$ & $p$-Value \\
\hline Major bleeding & $3(11.1)$ & $1(4.0)$ & 0.611 & $2(14.3)$ & $1(6.2)$ & 0.586 \\
\hline Clinically relevant non-major bleeding & $5(18.5)$ & $1(4.0)$ & 0.193 & $1(7.1)$ & $0(0.0)$ & 0.467 \\
\hline Clinically relevant bleeding & $8(29.6)$ & $2(8.0)$ & 0.078 & $3(21.4)$ & $1(6.2)$ & 0.315 \\
\hline \multirow[t]{3}{*}{ Total bleeding } & $10(37)$ & $2(8.0)$ & 0.020 & $6(42.9)$ & $2(12.5)$ & 0.101 \\
\hline & \multicolumn{3}{|c|}{ Hepatocellular carcinoma $(n=8)$} & & & \\
\hline & $\begin{array}{l}\text { Rivaroxaban } \\
\quad(\mathrm{n}=3, \%)\end{array}$ & $\begin{array}{c}\text { LMWH } \\
(\mathrm{n}=5, \%)\end{array}$ & $p$-Value & & & \\
\hline Major bleeding & $1(33.3)$ & $2(40.0)$ & 1.000 & & & \\
\hline Clinically relevant non-major bleeding & $1(33.3)$ & $0(0.0)$ & 0.375 & & & \\
\hline Clinically relevant bleeding & $2(66.7)$ & $2(40.0)$ & 1.000 & & & \\
\hline Total bleeding & $2(66.7)$ & $3(60.0)$ & 1.000 & & & \\
\hline
\end{tabular}

studies, active cancer was defined as a diagnosis of cancer in the previous 6 months, any treatment for cancer within the previous 6 months, recurrent or metastatic cancer, or hematological cancer not in complete remission; this implies that patients without a currently existing cancer lesion (e.g., surgically removed) at the beginning or during anticoagulation could also have been enrolled in those trials, which could be a bias in analyzing the bleeding risk related to the use of anticoagulant in patients with cancer. The rate of metastatic disease in the SELECT-D study and the 
Table VI. Bleeding sites according to type of anticoagulation in patients with clinically relevant bleeding.

\begin{tabular}{|c|c|c|c|}
\hline & $\begin{array}{c}\text { Rivaroxaban } \\
(\mathrm{n}=69, \%)\end{array}$ & $\begin{array}{c}\text { LMWH } \\
(\mathrm{n}=105, \%)\end{array}$ & $p$-Value \\
\hline Major bleeding & $12 / 69(17.4)$ & $8 / 105(7.6)$ & 0.048 \\
\hline GI sites & $12 / 12(100.0)$ & $4 / 8(50.0)$ & 0.014 \\
\hline Specific sites & & & 0.107 \\
\hline Stomach & $7 / 12(58.3)$ & $2 / 8(25.0)$ & \\
\hline Colon and rectum & $2 / 12(16.7)$ & $1 / 8(12.5)$ & \\
\hline Unspecified GI tract & $3 / 12(25.0)$ & $1 / 8(12.5)$ & \\
\hline Hemoperitoneum & $0 / 12(0.0)$ & $3 / 8(37.5)$ & \\
\hline Others & $0 / 12(0.0)$ & $1 / 8(12.5)^{\mathrm{a}}$ & \\
\hline $\begin{array}{l}\text { Clinically relevant } \\
\text { non-major bleeding }\end{array}$ & $10 / 69(14.5)$ & $7 / 105(6.7)$ & 0.089 \\
\hline GI sites & $6 / 10(60.0)$ & $5 / 7(71.4)$ & 1.000 \\
\hline Specific sites & & & 0.095 \\
\hline Stomach & $3 / 10(30.0)$ & 3/7 (42.9) & \\
\hline Colon and rectum & $0 / 10(0.0)$ & $2 / 7(28.6)$ & \\
\hline Unspecified GI tract & $1 / 10(10.0)$ & $0 / 7(0.0)$ & \\
\hline Biliary tract & $2 / 10(20.0)$ & $0 / 7(0.0)$ & \\
\hline \multicolumn{4}{|l|}{ Hemoperitoneum } \\
\hline Airway & $0 / 10(0.0)$ & $2 / 7(28.6)$ & \\
\hline Urinary tract & $3 / 10(30.0)$ & $0 / 7(0.0)$ & \\
\hline Others & $1 / 10(10.0)^{b}$ & $0 / 7(0.0)$ & \\
\hline Clinically relevant bleeding & $22 / 69(31.9)$ & $15 / 105(14.3)$ & 0.006 \\
\hline GI sites & $18 / 22(81.8)$ & 9/15 (60.0) & 0.142 \\
\hline Specific sites & & & 0.077 \\
\hline Stomach & $10 / 22(45.5)$ & $5 / 15(33.3)$ & \\
\hline Colon and rectum & $2 / 22(9.1)$ & $3 / 15(20.0)$ & \\
\hline Unspecified GI tract & $4 / 22(18.2)$ & $1 / 15(6.7)$ & \\
\hline Biliary tract & $2 / 22(9.1)$ & $0 / 15(0.0)$ & \\
\hline Hemoperitoneum & $0 / 22(0.0)$ & $3 / 15(20.0)$ & \\
\hline Airway & $0 / 22(0.0)$ & $2 / 15(13.3)$ & \\
\hline Urinary tract & $3 / 22(13.6)$ & $0 / 15(0.0)$ & \\
\hline Others & $1 / 22(6.7)$ & $1 / 15(4.5)$ & \\
\hline
\end{tabular}

GI: Gastrointestinal. aClinical deterioration with decreased hemoglobin (Hb 5.0) and death due to unknown cause. bVaginal bleeding.

Hokusai VTE cancer study was only 58\% and 53\%, respectively. Second, both studies included highly heterogeneous cancer types, while cancer types related to a relatively high bleeding risk, as well as a high VTE risk, were only a minor proportion. Reportedly, GI cancer, especially upper GI tract or pancreatobiliary cancers, are well known for having not only the highest VTE risk but also the highest risk of bleeding regardless of anticoagulation (20, 24). Indeed, in the Hokusai VTE cancer study, patients with GI cancer exhibited an increased risk of major bleeding during treatment with edoxaban than with dalteparin; $13.2 \%$ with edoxaban versus $2.4 \%$ with dalteparin in GI cancer and $4.7 \%$ with edoxaban versus $4.5 \%$ with dalteparin in non-GI cancer (interaction $p=0.02$ ) (18). Most cases of GI bleeding were noted in upper GI sites. Likewise, in the SELECT-D trial, most major bleeding events were on GI tract, and patients with esophageal or gastroesophageal cancer tended to experience more major bleeds with rivaroxaban $(36 \%)$ than with dalteparin (5\%) (17). These findings resulted in the halting of enrollment of patients with gastroesophageal cancer. As the proportion of patients with upper GI cancer, including upper GI tract and HPB cancer, was only $14 \%$ in the Hokusai VTE cancer study and $18 \%$ in the SELECT-D study, had more of these cancer types been included, the bleeding risk from DOAC could have been further increased.

Hence, this study investigated the efficacy and safety of rivaroxaban compared with LMWH as a treatment for cancer-associated VTE in patients with currently active, locally advanced unresectable, or metastatic upper GI tract or HPB cancer, providing more relevant data to guide the selection of anticoagulation in these high-risk patient populations. We observed that rivaroxaban correlated with a similar efficacy but with higher risk of bleeding compared with LMWH in these patients. The rate of major bleeding events with rivaroxaban (17.4\%) and dalteparin/enoxaparin (7.6\%) in this study seemed to be much higher than those of the SELECT-D study (5.4\% with rivaroxaban and $3.0 \%$ with dalteparin) and the Hokusai VTE cancer study (6.9\% with edoxaban and $4.0 \%$ with dalteparin), suggesting that the elevated bleeding risk from DOAC compared with LMWH in patients with cancer might be further elevated in high-risk patients with currently active, unresectable, or metastatic upper GI tract or HPB cancer. Corroborating previous studies, upper GI tract cancer was more susceptible to an elevated risk of major bleeding from rivaroxaban.

This study has some limitations. First, being a retrospective observational study, there could be potential biases in the characteristics of treatment groups, treatment compliance, or outcome events capture. To validate our study results, we are currently conducting a prospective study comparing DOAC with LMWH in the same study population (clinicaltrials.gov NCT03139487).

Although DOACs are used for the treatment of cancerassociated VTE in patients with advanced cancer, this study suggests that rivaroxaban has comparable efficacy but augmented bleeding risks compared with LMWH in patients with active locally advanced or metastatic upper GI tract or HPB cancer. In particular, the use of rivaroxaban in patients with upper GI tract cancer may require extra caution because of much higher bleeding risks.

\section{Conflicts of Interest}

The Authors have no conflicts of interest to declare regarding this study.

\section{Authors' Contributions}

Study concepts: Jwa Hoon Kim, Seyoung Seo, and Sook Ryun Park; Data collection: Seyoung Seo, Hyeon-Su Im, Hyehyun Jeong, and Yeonghak Bang; Patient management: Kyu-pyo Kim, Heung-Moon 
Chang, Baek-Yeol Ryoo, Changhoon Yoo, Jae Ho Jeong, Jae-Lyun Lee, and Sook Ryun Park; Data analysis and interpretation of results: Jwa Hoon Kim, Seyoung Seo, and Sook Ryun Park; Statistical analysis: Jwa Hoon Kim and Seyoung Seo; Manuscript writing: Jwa Hoon Kim, Seyoung Seo, and Sook Ryun Park; Manuscript reviewing: Seyoung Seo, Kyu-pyo Kim, Heung-Moon Chang, Baek-Yeol Ryoo, Changhoon Yoo, Jae Ho Jeong, Jae-Lyun Lee, Hyeon-Su Im, Hyehyun Jeong, Yeonghak Bang and Sook Ryun Park; Supervision of the study; Sook Ryun Park.

\section{Acknowledgements}

This study was supported by a grant (2017-0327) from the Asan Institute for Life Sciences, Asan Medical Center, Seoul, Republic of Korea.

\section{References}

1 Baron JA, Gridley G, Weiderpass E, Nyren O and Linet M: Venous thromboembolism and cancer. Lancet 351(9109): 10771080, 1998. PMID: 9660575. DOI: 10.1016/S0140-6736(97) 10018-6

2 Prandoni P, Lensing AW, Piccioli A, Bernardi E, Simioni P, Girolami B, Marchiori A, Sabbion P, Prins MH, Noventa F and Girolami A: Recurrent venous thromboembolism and bleeding complications during anticoagulant treatment in patients with cancer and venous thrombosis. Blood 100(10): 3484-3488, 2002. PMID: 12393647. DOI: 10.1182/blood-2002-01-0108

3 Hutten BA, Prins MH, Gent M, Ginsberg J, Tijssen JG and Buller HR: Incidence of recurrent thromboembolic and bleeding complications among patients with venous thromboembolism in relation to both malignancy and achieved international normalized ratio: a retrospective analysis. J Clin Oncol 18(17): 3078-3083, 2000. PMID: 10963635. DOI: 10.1200/JCO.2000.18.17.3078

4 Lee AY, Levine MN, Baker RI, Bowden C, Kakkar AK, Prins M, Rickles FR, Julian JA, Haley S, Kovacs MJ and Gent M: Low-molecular-weight heparin versus a coumarin for the prevention of recurrent venous thromboembolism in patients with cancer. N Engl J Med 349(2): 146-153, 2003. PMID: 12853587. DOI: $10.1056 /$ NEJMoa025313

5 Meyer G, Marjanovic Z, Valcke J, Lorcerie B, Gruel Y, SolalCeligny P, Le Maignan C, Extra JM, Cottu P and Farge D: Comparison of low-molecular-weight heparin and warfarin for the secondary prevention of venous thromboembolism in patients with cancer: a randomized controlled study. Arch Intern Med 162(15): 1729-1735, 2002. PMID: 12153376. DOI: 10.1001/archinte.162.15.1729

6 Lee AYY, Kamphuisen PW, Meyer G, Bauersachs R, Janas MS, Jarner MF and Khorana AA: Tinzaparin $v s$ warfarin for treatment of acute venous thromboembolism in patients with active cancer: a randomized clinical trial. JAMA 314(7): 677686, 2015. PMID: 26284719. DOI: 10.1001/jama.2015.9243

7 Lyman GH, Khorana AA, Kuderer NM, Lee AY, Arcelus JI, Balaban EP, Clarke JM, Flowers CR, Francis CW, Gates LE, Kakkar AK, Key NS, Levine MN, Liebman HA, Tempero MA, Wong SL, Prestrud AA and Falanga A: Venous thromboembolism prophylaxis and treatment in patients with cancer: American society of clinical oncology clinical practice guideline update. J Clin Oncol 31(17): 2189-2204, 2013. PMID: 23669224. DOI: $10.1200 / J C O .2013 .49 .1118$
8 Farge D, Bounameaux H, Brenner B, Cajfinger F, Debourdeau P, Khorana AA, Pabinger I, Solymoss S, Douketis J and Kakkar A: International clinical practice guidelines including guidance for direct oral anticoagulants in the treatment and prophylaxis of venous thromboembolism in patients with cancer. Lancet Oncol 17(10): e452-e466, 2016. PMID: 27733271. DOI: 10.1016/ S1470-2045(16)30369-2

9 Mandala M, Falanga A and Roila F: Management of venous thromboembolism (VTE) in cancer patients: ESMO clinical practice guidelines. Ann Oncol 22(Suppl 6): vi85-92, 2011. PMID: 21908511. DOI: 10.1093/annonc/mdr392

10 Buller HR, Prins MH, Lensin AW, Decousus H, Jacobson BF, Minar E, Chlumsky J, Verhamme P, Wells P, Agnelli G, Cohen A, Berkowitz SD, Bounameaux H, Davidson BL, Misselwitz F, Gallus AS, Raskob GE, Schellong $S$ and Segers A: Oral rivaroxaban for the treatment of symptomatic pulmonary embolism. N Engl J Med 366(14): 1287-1297, 2012. PMID: 22449293. DOI: $10.1056 /$ NEJMoa1113572

11 Bauersachs R, Berkowitz SD, Brenner B, Buller HR, Decousus H, Gallus AS, Lensing AW, Misselwitz F, Prins MH, Raskob GE, Segers A, Verhamme P, Wells P, Agnelli G, Bounameaux H, Cohen A, Davidson BL, Piovella F and Schellong S: Oral rivaroxaban for symptomatic venous thromboembolism. N Engl J Med 363(26): 2499-2510, 2010. PMID: 21128814. DOI: 10.1056/NEJMoa1007903

12 Agnelli G, Buller HR, Cohen A, Curto M, Gallus AS, Johnson M, Masiukiewicz U, Pak R, Thompson J, Raskob GE and Weitz JI: Oral apixaban for the treatment of acute venous thromboembolism. N Engl J Med 369(9): 799-808, 2013. PMID: 23808982. DOI: 10.1056/NEJMoa 1302507

13 Buller HR, Decousus H, Grosso MA, Mercuri M, Middeldorp S, Prins MH, Raskob GE, Schellong SM, Schwocho L, Segers A, Shi M, Verhamme P and Wells P: Edoxaban versus warfarin for the treatment of symptomatic venous thromboembolism. N Engl J Med 369(15): 1406-1415, 2013. PMID: 23991658. DOI: 10.1056/NEJMoa1306638

14 Schulman S, Kearon C, Kakkar AK, Mismetti P, Schellong S, Eriksson H, Baanstra D, Schnee J and Goldhaber SZ: Dabigatran versus warfarin in the treatment of acute venous thromboembolism. N Engl J Med 361(24): 2342-2352, 2009. PMID: 19966341. DOI: 10.1056/NEJMoa0906598

15 Prins MH, Lensing AW, Brighton TA, Lyons RM, Rehm J, Trajanovic M, Davidson BL, Beyer-Westendorf J, Pap AF, Berkowitz SD, Cohen AT, Kovacs MJ, Wells PS and Prandoni $\mathrm{P}$ : Oral rivaroxaban versus enoxaparin with vitamin $\mathrm{K}$ antagonist for the treatment of symptomatic venous thromboembolism in patients with cancer (EINSTEIN-DVT and EINSTEIN-PE): a pooled subgroup analysis of two randomised controlled trials. Lancet Haematol 1(1): e37-46, 2014. PMID: 27030066. DOI: 10.1016/S2352-3026(14)70018-3

16 Vedovati MC, Germini F, Agnelli G and Becattini C: Direct oral anticoagulants in patients with VTE and cancer: a systematic review and meta-analysis. Chest 147(2): 475-483, 2015. PMID: 25211264. DOI: $10.1378 /$ chest.14-0402

17 Young AM, Marshall A, Thirlwall J, Chapman O, Lokare A, Hill C, Hale D, Dunn JA, Lyman GH, Hutchinson C, MacCallum P, Kakkar A, Hobbs FDR, Petrou S, Dale J, Poole CJ, Maraveyas A and Levine M: Comparison of an oral factor Xa inhibitor with low molecular weight heparin in patients with cancer with venous thromboembolism: results of a randomized trial (SELECT-D). J 
Clin Oncol 36(20): 2017-2023, 2018. PMID: 29746227. DOI: 10.1200/JCO.2018.78.8034

18 Raskob GE, van Es N, Verhamme P, Carrier M, Di Nisio M, Garcia D, Grosso MA, Kakkar AK, Kovacs MJ, Mercuri MF, Meyer G, Segers A, Shi M, Wang TF, Yeo E, Zhang G, Zwicker JI, Weitz JI and Buller HR: Edoxaban for the treatment of cancer-associated venous thromboembolism. N Engl J Med 378(7): 615-624, 2018. PMID: 29231094. DOI: 10.1056/ NEJMoa1711948

19 Pabinger I, van Es N, Heinze G, Posch F, Riedl J, Reitter EM, Di Nisio M, Cesarman-Maus G, Kraaijpoel N, Zielinski CC, Buller HR and Ay C: A clinical prediction model for cancerassociated venous thromboembolism: a development and validation study in two independent prospective cohorts. Lancet Haematol 5(7): e289-e298, 2018. PMID: 29885940. DOI: $10.1016 / \mathrm{S} 2352-3026(18) 30063-2$

20 Patell R, Gutierrez A, Rybicki L and Khorana AA: Identifying predictors for bleeding in hospitalized cancer patients: a cohort study. Thromb Res 158: 38-43, 2017. PMID: 28820967. DOI: 10.1016/j.thromres.2017.08.005

21 Schulman S and Kearon C: Definition of major bleeding in clinical investigations of antihemostatic medicinal products in non-surgical patients. J Thromb Haemost 3(4): 692-694, 2005. PMID: 15842354. DOI: 10.1111/j.1538-7836.2005.01204.x
22 National Comprehensive Cancer Network 2019: CancerAssociated Venous Thromboembolic Disease Version 1.2019. Available at: http://www.nccn.org/professionals/physician_gls/ $\mathrm{pdf} /$ vte.pdf

23 Lyman GH, Bohlke K, Khorana AA, Kuderer NM, Lee AY, Arcelus JI, Balaban EP, Clarke JM, Flowers CR, Francis CW, Gates LE, Kakkar AK, Key NS, Levine MN, Liebman HA, Tempero MA, Wong SL, Somerfield MR and Falanga A: Venous thromboembolism prophylaxis and treatment in patients with cancer: american society of clinical oncology clinical practice guideline update 2014. J Clin Oncol 33(6): 654-656, 2015. PMID: 25605844. DOI: 10.1200/JCO.2014.59.7351

24 Khorana AA, Kuderer NM, Culakova E, Lyman GH and Francis $\mathrm{CW}$ : Development and validation of a predictive model for chemotherapy-associated thrombosis. Blood 111(10): 4902-4907, 2008. PMID: 18216292. DOI: 10.1182/blood-2007-10-116327

Received December 24, 2019

Revised January 5, 2020

Accepted January 6, 2020 